2010-03-01

\title{
Free: Why Authors are Giving Books Away on the Internet
}

John L. Hilton III

johnhiltoniii@byu.edu

David Wiley

david.wiley@gmail.com

Follow this and additional works at: https://scholarsarchive.byu.edu/facpub

Part of the Educational Psychology Commons

\section{Original Publication Citation}

Hilton, J. \& Wiley, D. (21). Free: Why authors are giving books away on the Internet. Tech Trends, 54(1).

\section{BYU ScholarsArchive Citation}

Hilton, John L. III and Wiley, David, "Free: Why Authors are Giving Books Away on the Internet" (2010). Faculty Publications. 825.

https://scholarsarchive.byu.edu/facpub/825 accepted for inclusion in Faculty Publications by an authorized administrator of BYU ScholarsArchive. For more information, please contact ellen_amatangelo@byu.edu. 


\title{
Free: Why Authors are Giving Books Away on the Internet
}

\author{
By John Hilton III and David Wiley
}

\begin{abstract}
With increasing frequency, authors in academic and non-academic fields are releasing their books for free digital distribution. Anecdotal evidence suggests that exposure to both authors and books increases when books are available as free downloads, and that print sales are not negatively affected. For this study we interviewed ten authors to determine their perceptions of the effect free digital distribution has on the impact and sales of their work. In addition, we examined the sales data of two books over a two year period of time, in which one book was freely available for the second year. All of the individuals we surveyed felt free digital downloads increased the distribution and impact of their book. None of the authors felt that print sales were negatively affected. Data from our book sale comparison suggest that in the case we studied, free digital distribution did not negatively affect sales.
\end{abstract}

Keywords: Open educational resources, online technology, digital publishing

What happens to book sales if digital versions of the book are given away for free on the Internet? Anecdotal evidence suggests that in some cases the visibility of the author and sales of physical products increase when digital versions are freely distributed on the Internet (Doctorow, 2008a, Hardawar, 2009, Kusek, 2008). Yet some authors suspect that giving away free copies of books may negatively affect how people perceive the value of print books (Adams, 2007). The question of how freely distributing an electronic version of a work affects print sales is impossible to answer through experimental research because there is no way to simultaneously release and prevent the release of free versions of a book.
Nevertheless, the effect of free distribution on print sales is an important question to explore.

A growing number of authors are using free digital distribution of their books in order to increase the visibility of their work. These authors include individuals writing to both academic and general audiences in a wide variety of genres, including technology, law, education, and science fiction. Many of these authors openly license their works. These open licenses allow authors to give away some rights (such as allowing users to email a copy of the book to a friend) while retaining other rights (such as prohibiting commercial use). The Creative Commons licenses are the

"A growing number of authors are using free digital distribution of their books in order to increase the visibility of their work." most frequently employed openly licenses (e.g., Flickr shows over 100 million photos licensed this way (Benenson, 2009)). These licenses have been discussed at length in many places (Bissell, 2009, Creative Commons, 2009).

In the present study we sought to explore digital book distribution by asking the following five questions.

1. What motivates authors to provide free digital versions of books?

2. How does free digital distribution affect the distribution of a work?

3. How does free digital distribution affect the impact of a work?

4. Are authors glad they made their books freely available?

5. What effect does free digital distribution have on print sales? 


\section{Method}

We examined the above questions in three different ways. First, we reviewed published comments by authors who have openly licensed their books. Second, we emailed a questionnaire to these authors. This was a snowball survey in which we asked authors to recommend other au-

\section{"Does free distribution} increase exposure? Every author we surveyed said yes." thors for the study. In total, we invited fourteen authors to participate in our survey and ten did so. The main reason authors declined participating is that their openly-published work had not been available for a sufficient period of time, and they felt that their participation would be premature. Throughout this article any statement attributed to an author that is not otherwise referenced came from the surveys we conducted. Our third method was examining book sales data of two books by Lawrence Lessig. A free digital version of one of these books was made available in January 2008, and the second book was used as a comparison.

In accordance with the open theme of the research, authors participated in the survey with the understanding that their comments would be attributed to them, and that no attempts would be made to protect their identities. The following authors completed the survey. We include the titles of some of the books they have "openly published" as context for the reader.

1. Hal Abelson (Structure and Interpretation of Computer Programs, Blown to Bits).

2. Yochai Benkler (The Wealth of Networks).

3. James Boyle (The Shakespeare Chronicles, Bound by Law, The Public Domain).

4. Cory Doctorow (Down and Out in the Magic Kingdom, A Place So Foreign and Eight More, Eastern Standard Tribe, Someone Comes to Town, Someone Leaves Town, Little Brother, Overclocked: Stories of the Future Present, Content).

5. Leander Kahney (The Cult of Mac, The Cult of iPod).

6. Chris Kelty (Two Bits: The Cultural Significance of Free Software and the Internet).

7. Lawrence Lessig (Code, Free Culture, The Future of Ideas).

8. Kembrew McLeod (Freedom of Expression).

9. Eric Schulman (A Briefer History of Time).

10. Eric Von Hippel (The Sources of Innovation, Democratizing Innovation).

Authors' Motivations For

Free Book Distribution

When asked what motivates them to openly publish their works, authors responded most fre- quently that (1) they had a desire to increase the exposure of the book, and (2) open publishing is, morally speaking, the right thing to do.

Boyle said of his motivations, "Scholars have a professional responsibility to make their works as widely available, without price barriers, as is possible." In addition to this moral reasoning, he said that because of open licensing, "I reach new audiences that I couldn't have imagined [and] I think I'll sell more books."

Kahney responded, "I felt like had taken a lot from the Mac community and in the spirit of giving it kind of gave back. It [also] seems forward thinking. [I had] nothing to lose [and] wanted to see what would happen."

Lessig said he was persuaded to openly publish Free Culture because he felt it would increase the dissemination of his ideas; in addition, his publisher encouraged him to try it because of the close connection between the topic of the book and openness.

Doctorow (2008b) stated that he had multiple motivations for open publishing. He said, "Giving away ebooks gives me artistic, moral and commercial satisfaction" (p. 4).

Benkler and Abelson used exactly the same words to describe their motivations for openly licensing by simply stating that it was "the right thing to do."

\section{Implications of Open Publishing on the Distribution of a Work}

Publisher Tim O'Reilly once quipped that, "Obscurity is a far greater threat to authors and creative artists than piracy" (O'Reilly, 2007). Does free distribution increase exposure? Every author we surveyed said yes.

Lessig said, "The number of people who tell me they would never have seen the book had it not been freely licensed is extraordinary."

Kelty explained, "I would say that it has been significant, though not dramatic. Responses to the book have come from all over the world, including markets where Duke [University Press] does no marketing (like Korea and Argentina), and all of the reviews have mentioned that it is freely available."

Schulman said, "I believe more people have read my book because I made it available in this way."

In addition, Doctorow (2008a) has written, "Most people who download [a book I wrote] don't end up buying it, but they wouldn't have bought it in any event, so I haven't lost any sales, I've just won an audience...After all, distributing nearly a million copies of my book has cost me nothing. The thing about an ebook is that it's a social object. It wants to be copied from 
friend to friend, beamed from a Palm device, pasted into a mailing list" (71).

\section{Implications of Open Publishing on the Impact of a Work}

Closely connected with the distribution of a book is the impact it has. Lawrence Lessig of Stanford University published Free Culture in 2004. The book has sold tens of thousands of copies since being released. However, the book has been downloaded several hundred thousand times. Perhaps more importantly, Hilton (2009) reports that it "has been translated into seven different languages, audio versions are freely available, and it has been put into sixteen different ebook formats. All of these translations and format changes are freely available for others to download. Allowing others to remix Free Culture vastly expanded its reach."

Mcleod has had about 50,000 download of Freedom of Expression just from his site. Mcleod said, "I think that openness has extended the long tail of my book. It may not have sold a large amount when it was first released, but it continues to sell well. I think part of that is the visibility that open licensing created and the good will it has created."

In answer to the question, "What effect (if any) has open licensing had on your reputation as an author or publisher?" Benkler said, "It has probably exposed me to people who otherwise would not have gravitated towards an academic book."

In addition to increasing the impact of a specific book, open publishing has the potential to enhance an author's reputation. Boyle (2007) wrote, "Even professional authors make money in multiple ways other than by royalties - ranging from options on film production to commissions for magazine articles to consulting, teaching and speaker fees. Most are aided by wider exposure."

\section{Author Attitudes Toward Open Publishing}

We asked authors if they were happy with their decision to give their books away online and if they will do it again.

Mcleod affirmed, "Absolutely. It makes me feel like a better person. It strokes my ego when someone from Africa or Sweden emails me. It's been absolutely positive experience; I'd recommend it to everyone."

Von Hippel agreed. "Very glad. Will only openly license in future."

Kelty said, "Absolutely. I would have lost the respect of the community that I study if I hadn't, and I wouldn't be able to urge my colleagues, students and peers to do the same with their work without clear evidence that it is a good idea."
Schulman answered, "Yes, I am. I wrote the book so it would be read, and more people have now read it."

Doctorow agreed in a three-part answer. "1. It's made me more money. 2. If you're making art that's not intended to be copied, you're not making contemporary art. Artists have to come to grips with their time. It's an essential characteristic of contemporary art that if it has value, someone will copy it. 3. We're all pirates. Everyone copies things... When I was a teenager if it hadn't been for mixtapes I would probably never have had a relationship. [It is hypocritical] for me

\section{"A key question in open publishing is concerned with the effect open licensing has (if any) on print sales."} to turn around to someone else and say 'when we did it, it was just good fun, when you do it with 0 s and 1 s you're evil."'

Using the same language as others, Lessig concurred, "Absolutely."

Boyle felt that open licensing of his book has had an enormous effect. He was pleased that "multiple formats [of The Public Domain] have been put up by strangers (including a version for the blind)." This would not have been possible if he had not given away the book.

Benkler responded, "Yes. It was the right thing to do, and it persuaded the Press that they should do the same for other authors working on copyright, internet etc. subjects, and it helped others in their negotiations with academic presses."

Kahney was glad with his decision. "Yes. I totally am, it helped my reputation as an author and as an editor at WIRED.COM."

Abelson summed up the feelings of many of the authors, saying, "Yes. Because it was the right thing to do."

\section{Financial Implications of Open Publishing}

None of these authors felt that open publishing had a negative effect on sales; rather, most believed that openly publishing books would increase sales. How is it that open publishing could lead to increased sales? Doctorow (2008a wrote, "A tiny minority of downloaders treat the free ebook as a substitute for the printed book - those are the lost sales. But a much larger minority treat the ebook as an enticement to buy the printed book. They're gained sales. As long as gained sales outnumber lost sales, I'm ahead of the game...The number of people who wrote to me to tell me about how much they dug the ebook and so bought the paper book far exceeds the number of people who wrote to me and said, "Ha, ha, you hippie, 
I read your book for free and now I'm not gonna buy it."' (Pp. 71, 72, 110).

Some authors felt that free distribution increased awareness, which drove book sales. For example, Von Hippel reported that sales of his book were double the publisher's initial estimates. In addition to these sales, Von Hippel's was downloaded 90,000 times from his website.

Boyle (2007) wrote, "Why might free digital availability make sense for parts of the publishing industry? First, most people hate reading a book on a screen, but like finding out if it is worth buying. I am sure I have lost some sales, but my guess is that I have gained more new readers who otherwise would be unaware of my work, and who treat the digital version as a "sampler," to which they then introduce others."

\section{Financial Implications of Open Publishing: A Case Study}

A key question in open publishing is concerned with the effect open licensing has (if any) on print sales. Following the pattern of a study done by O'Reilly (2007), we used Nielsen Bookscan to gauge the impact of free digital distribution on book sales. Bookscan tracks point-of-sale data from most major book sellers, meaning that it tracks the number of books actually sold to customers as opposed to books sold by distributors to retailers. Notable book sellers that Bookscan does not track include Wal-Mart, Sam's Club, and many drug and grocery stores (Milliot and Zeitchik, 2004). Depending on the type of book being sold, this can create varying degrees of inaccuracy in Bookscan data. In general, Bookscan estimates that it tracks approximately $70 \%$ of all book sales in the United States.

We used Bookscan to analyze the sales of Lawrence Lessig's book The Future of Ideas first published in 2001. This book was selected because there was a clear point at which this book, which had formally been available only in print, was released in a free digital format. On January 14, 2008 Lessig announced that his book The Future of Ideas, had been openly licensed (Lessig, 2008). Our question was, what impact (if any) did distributing the book for free online have on print sales of the book?

In order to answer this question we analyzed the sales data of The Future of Ideas for the year before and after it was openly licensed. Because book sales tend to decrease as time goes on, it seemed reasonable that sales would decrease. But how much of a decrease should be expected?

Another of Lessig's books, Free Culture, is a fairly comparable book. Released in 2004, Free Culture has always been available under an open license. Therefore there would be no significant sales impact from 2007-2009 based on a change in the license. In addition, the comparison could be made without having to worry about differences in sales based on author popularity, although it is acknowledged that these were different books and may have had different audiences. In addition to analyzing these two books we used Bookscan data on the total adult non-fiction book sales in the years 2007-2009 to see whether economic conditions affected total adult nonfiction book sales in these years. According to Bookscan, total adult nonfiction sales declined by $4 \%$ between 2007 and 2008 .

Bookscan data is organized by week. We organized the weeks into groups of thirteen, giving four quarters for each year. Because The Freedom of Ideas was released one week into 2008, we begin counting with the second week of January. According to Bookscan, the sales of Free Culture from January 8, 2007 to January 6, 2009 are as follows:

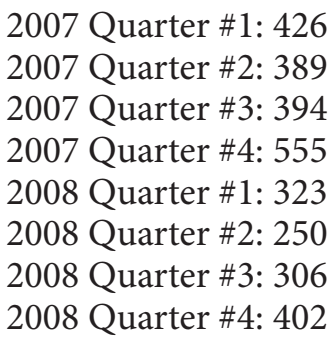

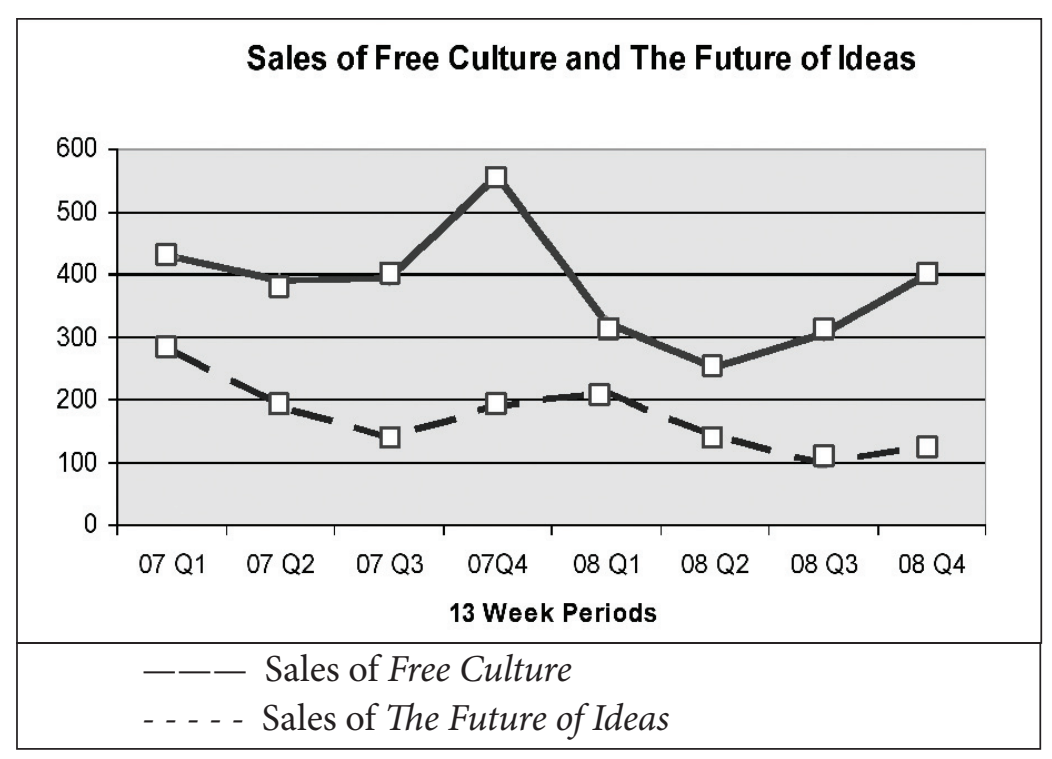

Figure 1. 
According to Bookscan, the sales of The Future of Ideas during this same time period are as follows:

2007 Quarter \#1: 276

2007 Quarter \#2: 188

2007 Quarter \#3: 135

2007 Quarter \#4: 188

2008 Quarter \#1: 208

2008 Quarter \#2: 139

2008 Quarter \#3: 96

2008 Quarter \#4: 123

Figure 1 shows the quarter-by-quarter sales of Free Culture and The Future of Ideas over this two year period of time:

One notices from the graph in Figure 1 that the two books seem to follow a similar sales pattern. Our most surprising finding occurred when we aggregated the sales for each of these books in the year before and after The Future of Ideas was openly released.

Free Culture sold 1,764 copies in first four quarters of this study and 1,281 copies in the second four quarters. As a percentage, Free Culture sold $72.6 \%$ as many books in 2008 as in 2007. The Future of Ideas sold 787 copies in first four quarters of this study and 566 copies in the second four quarters. As a percentage, The Future of Ideas sold $71.9 \%$ as many books in 2008 than 2007.

Based on this data, the decline in sales of The Future of Ideas was 1\% less than the decline of sales of Free Culture. If openly releasing a book causes sales to decrease, we would expect a much sharper decline than was seen in book sales of The Future of Ideas. This is particularly true considering that The Future of Ideas is three years older than Free Culture. Although sales of both The Future of Ideas and Free Culture are declining, this is to be expected for books that have been in print for five and eight years respectively.

Because Free Culture had been openly released for years we would expect there to be no "openness" effect in its sales. Although it is impossible to know what would have happened to sales of The Future of Ideas had it not been openly released, our analysis of the sales data do not indicate a significant negative effect on sales. Of course, this line of argument would be strengthened by additional analysis of sales of additional books, and this analysis cannot necessarily be generalized to other books. Hilton and Wiley (in press) have begun further explorations in this area.

\section{Conclusion}

All of the individuals we surveyed were glad they had openly licensed their works. Clear motivations for open publishing were the opportunity to increase the exposure of their work, and a feeling that it was the right thing to do. All of the authors we surveyed felt that openly licensing their book significantly in-

\section{Author Questionnaire}

1. With whom did the idea to openly license your book(s) originate (the author or the publisher)?

2. If openly licensing the book was your idea, what motivated you to do so?

3. If the idea to openly license the book originated with you, what did you need to do to get the publisher or author to agree to openly license the book?

4. If openly licensing the book was not your idea, what persuaded you to do it?

5. What kind of connection (if any) is there between the topic of your book and openness?

6. What effect (if any) has open licensing had on the visibility or reach of your book?

7. What effect (if any) has open licensing had on your reputation as an author or publisher?

8. What effect (if any) has openly licensing the book had on sales?

9. What comparative information (if any) do you have on sales of comparable books that were not openly licensed?

10. Are you glad that you openly licensed the book? Why or why not?

11. What data (if any) do you have on the number of times that the book has been downloaded? How does this compare to the number of hard copies sold?

12. What lessons did you learn from openly licensing this (or any previous books you openly licensed) that you would apply to future projects?

13. What do you see as the future with regard to the open licensing and publishing of books?

14. Are there other authors or publishers you would recommend we speak with?

15. Are you aware of any research or literature about the open licensing of books?

16. What else do you think we should know about the open licensing of books? 
creased the distribution, impact, and exposure of the book. None of these authors felt that openly releasing the book had negatively affected sales.

Our case study indicates that openly releasing The Future of Ideas had no negative impact on sales; however, as stated previously, this conclusion cannot be stated with certainty, nor can it be generalized to other books. Furthermore, as books become increasingly available in digital formats the effects of free distribution may rapidly change. In order to more fully understand how open licensing affects print sales, further research needs to be done. Possible areas that may prove fruitful include: (1) comparing sales of books that have been released in a series, in which the previous non-openly released books have an established sales track record, and (2) using interrupted time series data similar to what was done with Lessig's books with multiple books.

It seems possible that the majority of those who download books would not have purchased the book, and that this downloading gives authors and publishers visibility that they would otherwise not have received, while not negatively affecting their sales. As the industry of electronic publishing matures it will be increasingly important to research the effects of free distribution of electronic books. "Free" may have important implications for authors who want to increase the impact of their work (Anderson, 2008).
John Hilton III received his M.Ed from the Harvard Graduate School of Education and currently is a Ph.D student in Instructional Psychology at Brigham Young University. He is interested in researching open-access issues, particularly the creation and use of open educational resources, and looking at how free digital book distribution affects print sales and the impact of books.

David Wiley is an associate professor of Instructional Psychology and Technology at Brigham Young University. His previous appointments include the director of the Center for Open and Sustainable Learning, a nonresident fellow of the Center for Internet and Society at Stanford Law School, a National Science Foundationfunded postdoctoral fellowship, and a visiting scholar appointment at the Open University of the Netherlands. He is also the recipient of the National Science Foundation's prestigious Young Researcher/CAREER award.

\section{References}

Adams, S. (2007, Nov. 1). Giving stuff away on the Internet. The Wall Street Journal, p. A19.

Anderson, C. (2008, February 25). Free! Why $\$ 0.00$ is the future of business. Retrieved from http://www.wired.com/techbiz/it/ magazine/16-03/ff_free?currentPage=all

Benenson, F. (2009, March 23). Celebrate 100 million CC photos on Flickr with Joi Ito's Free Souls. Retrieved from http://creativecommons.org/weblog/entry/12540

Bissell, A. (2009). Permission granted: Open licensing for educational resources. Open Learning, The Journal of Open and Distance Learning, 24, 97-106.

Boyle, J. (2007, January 22) Text is free, we make our money on volume(s). Retrieved from http://www.ft.com/cms/s/2/b46f5a58aa2e-11db-83b0-0000779e2340.html
Creative Commons (2009). Creative Commons Licenses. Retrieved from: http://creativecommons.org/about/licenses/meet-the-licenses.

Doctorow, C. (2008a). Content: Selected Essays on Technology, Creativity, Copyright, and the Future of the Future. San Francisco: Tachyon Publications.

Doctorow, C. (2008b). Little Brother. New York: Tor Teen.

Hardawar, D. (2009, January 23). Free Monty Python videos on Youtube lead to 23,000\% DVD sale increase. Retrieved from http:// www.slashfilm.com/2009/01/23/free-monty-python-videos-on-youtube-lead-to23000-dvd-sale-increase/

Hilton J., (2009). "From PDF to MP3: Motivations for creating derivative works." First Monday, Volume 14: No. 9 (2009).

Hilton, J., Wiley, D. (in press). “The short-term influence of free digital versions of books on print sales." The Journal of Electronic Publishing.

Kusek, D. (2008, January 19). The proof is in the pudding - Corey Smith. Retrieved from http://www.futureofmusicbook. com/2009/01/19/the-proof-is-in-the-pudding-corey-smith/.

Lessig, L. (2008, January 15). The Future of Ideas is now free. Retrieved from: http:// www.lessig.org/blog/2008/01/the_future_ of_ideas_is_now_fre_1.html

Milliot, J. and Zeitchik, S. (2004, January 12). Bookscan: Acceptance, and questions, grow. Publishers Weekly. Retrieved from: http://www.publishersweekly.com/article/ CA374063.html

O'Reilly, T. (2007, June). Free downloads vs. sales: A publishing case study - O'Reilly Radar. Retrieved from http://radar.oreilly. com/archives/2007/06/free-downloads-vssales-a-publ.html. 


\section{Read the Bottom Line.}

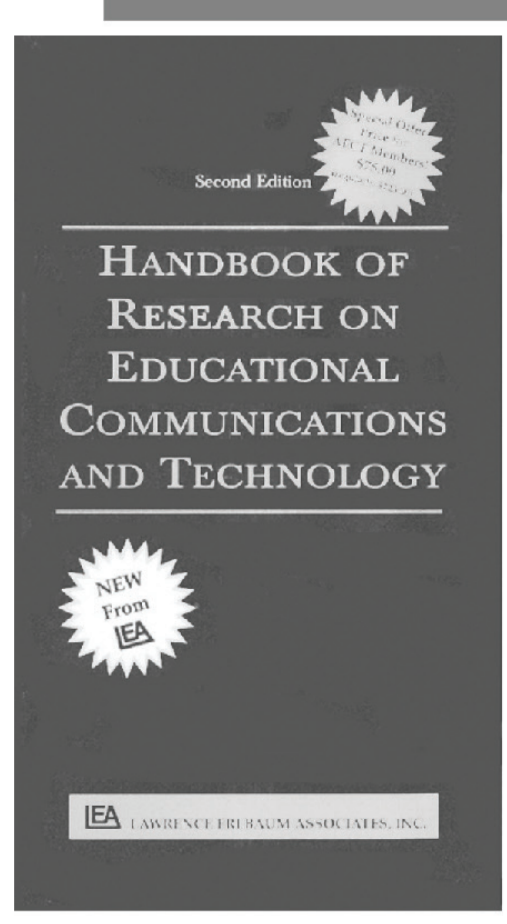

Get the last

word in

terminology,

technology

and tools of

the trade!

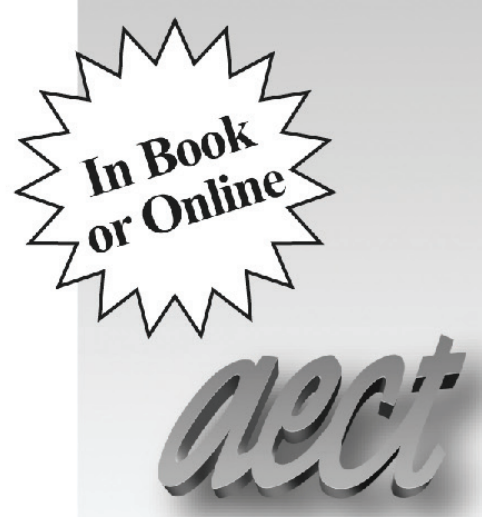

1800 Stonelake Dr. Suite 2

Bloomington, IN 47404

\section{Handbook of Research on Educational Communications and Technology Third Edition}

\author{
Edited by
}

Michael Spector

University of Georgia

$\mathrm{S}$

ponsored by the Association of Educational Communication and Technology (AECT), the second edition of this ground-breaking handbook updates and expands its review of the research, theory, issues, and methodology that constitute the field of educational communications and technology. Organized into seven sections, it profiles and integrates the following elements of this rapidly changing field: theoretical foundations, hard technologies, soft technologies, instructional design, instructional strategies, instructional message design, and research methodologies. All chapters have been updated, some extensively. New chapters include those on programmed instruction, everyday cognition and situated learning, ecological psychology, internet-based learning, library media centers, foreign language labs, microworlds, automated instructional design, cognitive apprenticeship, case-based learning aids, and conversational analysis. All articles are organized around a numerical cross-referencing system that permits the construction of front-end databases, hypertexts, and summaries.

This handbook is intended for graduate students, professors, instructional designers and researchers in educational communication and technology.

To order: You can order online at the AECT store at www.aect.org, or by calling toll-free 877-677-AECT. Member price: $\$ 115$ (incl. \$10 shipping); (phone orders only). 